\title{
Reliability of out-patient hysteroscopy in one-stop clinic for abnormal uterine bleeding
}

\author{
Atef M. Darwish • Ezzat H. Sayed • \\ Safwat A. Mohammad • Ibraheem I. Mohammad • \\ Hoida I. Hassan
}

Received: 3 January 2012 / Accepted: 30 January 2012 /Published online: 18 February 2012

(C) Springer-Verlag 2012

\begin{abstract}
This study aims to estimate the effect of adding office hysteroscopy to the preoperative diagnostic work-up in abnormal uterine bleeding on the diagnostic accuracy. It is a prospective comparative diagnostic trial at a tertiary care referral facility and a university hospital. There were a total of 295 patients, more than 35 years old, with abnormal uterine bleeding. The patients had vaginal sonography, office hysteroscopy, and office endometrial biopsy on onestop bases. The diagnostic accuracy of each method in diagnosing focal lesion and endometrial hyperplasia was measured as the main outcome of this paper. Combined hysteroscopy and biopsy were taken as the gold standard for diagnosing focal lesion while endometrial biopsy alone was the gold standard for diagnosing endometrial hyperplasia. Office hysteroscopy was superior to other methods for diagnosing focal lesion with about half of the focal lesions failing to be diagnosed with the other two methods. Office hysteroscopy was superior to vaginal sonography in diagnosing endometrial hyperplasia. Office hysteroscopy is an indispensable tool for diagnosing abnormal uterine bleeding and without its use, half of the focal lesions could be missed. Office setting and the one-stop approach greatly facilitate the use of the combination of office hysteroscopy with vaginal sonography and office endometrial sample.
\end{abstract}

A. M. Darwish $(\varangle) \cdot$ E. H. Sayed - S. A. Mohammad •

I. I. Mohammad

Department of Obstetrics and Gynecology,

Woman's Health University Hospital,

71111 Assiut, P.O. Box: (1) Assiut, Egypt

e-mail: atef_darwish@yahoo.com

H. I. Hassan

Department of Pathology, Faculty of Medicine, Assiut University,

Assiut, Egypt
Keywords Office hysteroscopy · Uterine bleeding · Ultrasonography · Biopsy

\section{Introduction}

Abnormal uterine bleeding (AUB) is any vaginal bleeding unrelated to normal menstruation and represents a major gynecological problem in about $20 \%$ of all gynecological referrals [1]. Anatomic and histologic causes predominate after the age of 35 years which made the American College of Obstetrics and Gynecology recommend endometrial biopsy as a part of investigating any woman with AUB above 35 years and sometimes earlier if there is a risk factor [2]. In addition to a careful clinical examination, the traditional approach for diagnosis of AUB comprises both transabdominal ultrasonography (TAS) and transvaginal ultrasonography (TVS), and endometrial sampling. Ultrasonography, especially TVS, is generally accepted as an initial investigation of these patients as it is well tolerated, least invasive, easy to do, and gives idea about the uterine anatomy (the wall and the lining) and the adnexa with little cost. These diagnostic tools share some common disadvantages in the form of failure to diagnose minute causes that are not commonly seen, to localize the exact site of the lesion causing bleeding, to define its relationship to tubal ostea specially in infertile women and lastly to guide biopsy aid. For cavitary disorders, hysteroscopy is the gold standard for diagnosis of AUB which is widely performed as office hysteroscopy $(\mathrm{OH})$ procedure with the possibility of see and treat in the setting. $\mathrm{OH}$ is a well-tolerated procedure and equally accepted as hysteroscopy under general anesthesia [3]. There is no consensus however that $\mathrm{OH}$ should be included in the initial evaluation of patients with AUB or be restricted to those with abnormalities at TVS. This study 


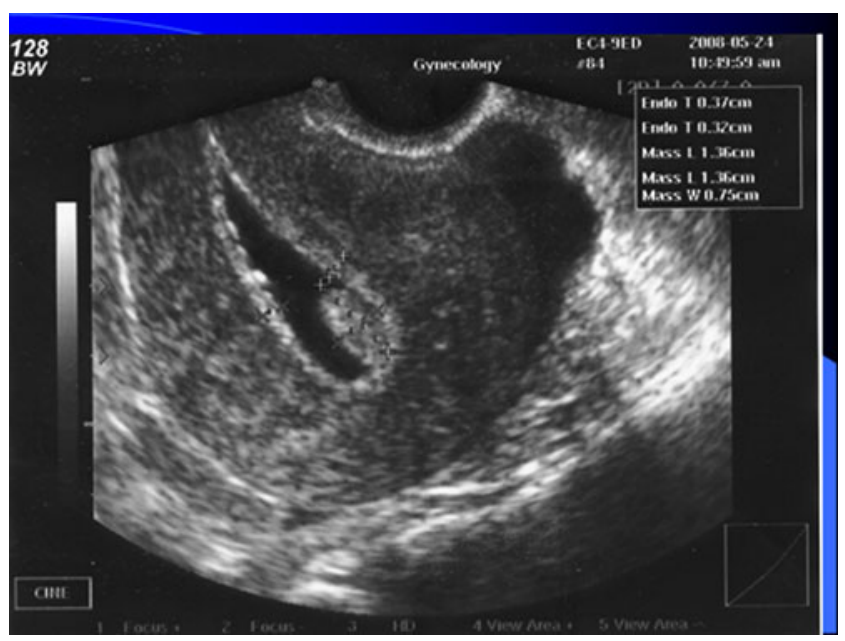

Fig. 1 Transvaginal sonohysterographic appereance of an endometrial polyp

aims to estimate the effect of adding $\mathrm{OH}$ to the preoperative diagnostic work-up in AUB on the diagnostic accuracy.

\section{Materials and methods}

After obtaining the acceptance of the ethics committee of the Assiut Faculty of Medicine, this study was conducted in the outpatient hysteroscopy unit of Woman's Health University Hospital from August 2006 to May 2011. It included women with AUB of 35 years or older. Exclusion criteria included suspected pregnancy, active pelvic infection, severe comorbidity, e.g., severe cardiac, neurologic, or chest disease, recent initiation of contraception in the previous 3 months, or cervical neoplasm. The patients were examined at the day of presentation on one-stop bases irrespective of the day of the cycle. All patients had clear description of the study and were asked to participate. An informed consent was taken from those who agreed.

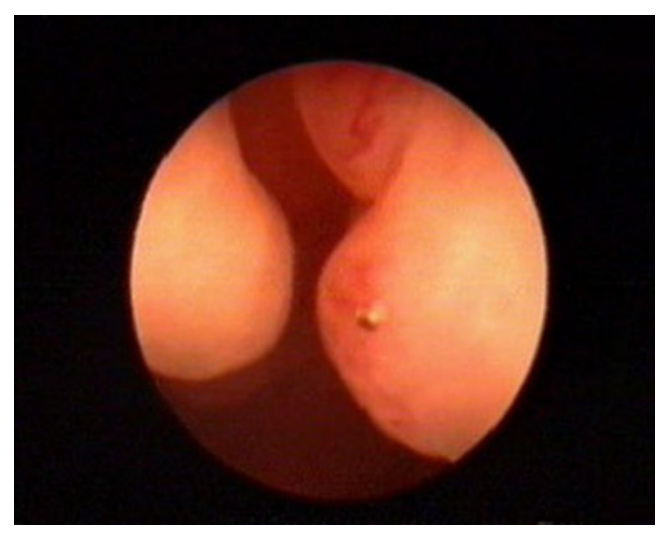

Fig. 2 Kissing endometrial polyp

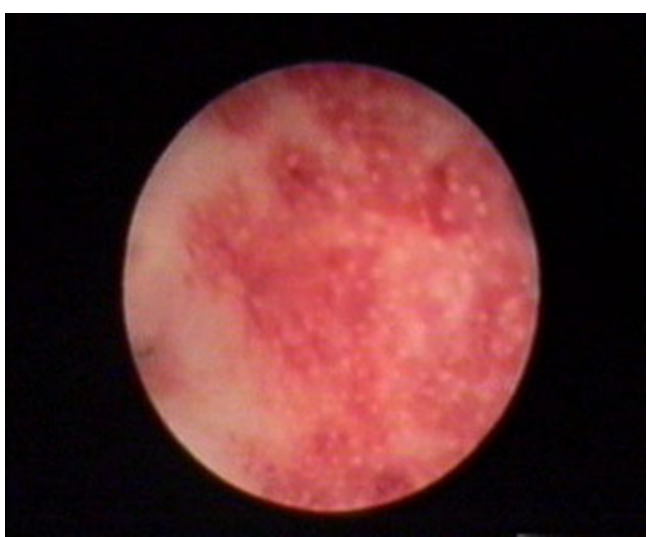

Fig. 3 Strawberry appearance of the congested endometrium

The included patients were subjected to complete history taking and meticulous physical examination. Both TAS and TVS were thereafter performed using a Medison $128 \mathrm{BW}$ machine (MEDISON COR, South Korea). The uterus was examined in the saggital and coronal views for endometrial thickness, focal cavitary or intramural masse(s), evidence of adenomyosis uteri [4], or adnexal mass(s).

The endometrium was considered thick when it was $5 \mathrm{~mm}$ or more in postmenopausal patients and in premenopausal patients of $8 \mathrm{~mm}$ or more and $10 \mathrm{~mm}$ or more cutoff levels was tested. Because it was not possible in all cases to clearly discriminate between polyp and submucous myoma, focal lesion was used to describe either of them. Abnormal endometrium was used to describe endometrial line with which was either thick and/or shows signs of focal lesion. In case of suspicious diagnosis when TVS could not exactly differentiate intracavitary from intramural lesions, a quick office sonohysterography was performed according to our simplified technique [5] as shown in Fig. 1. TVS was performed by an ultrasonography team but sonohysterography was performed by the first author.

$\mathrm{OH}$ was done using posterior wall Sims' speculum to expose the cervix where the anterior lip is grasped with

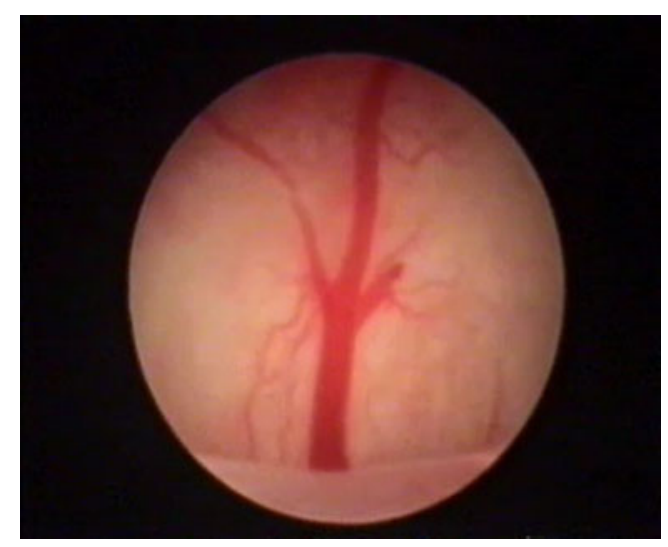

Fig. 4 Telangiectatic vessel of the endometrium 
Fig. 5 Office sampling

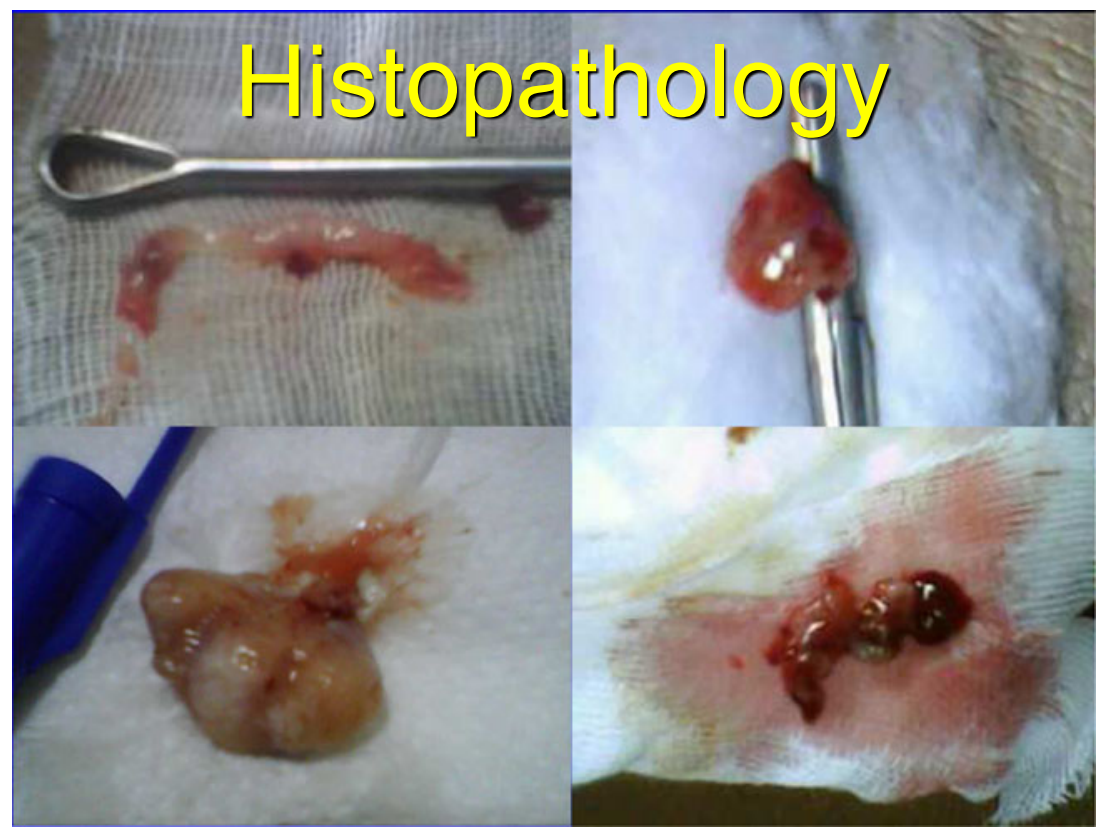

single-toothed tenaculum without any premedication or local anesthesia. We used $2.9^{\circ} \mathrm{mm} 30^{\circ}$ rigid scope with $4 \mathrm{~mm}$ single flow sheath (Promis, Germany) and the uterus was distended with normal saline at $100 \mathrm{mmHg}$ generated from a pneumatic cuff of sphygmomanometer. We used 250-W halogen light source for the video $\mathrm{OH}$. The scope was introduced gently through the cervical canal without previous dilatation using the saline to expand the way in front of the scope. The cervical canal was examined for polypi, Nabothian cysts, or micropolypi suggestive of chronic cervicitis. The uterine cavity was examined systematically (panoramic view) starting by its anterior and posterior walls; the fundus, and the borders and examination was considered complete if the both tubal ostia were reached describing any gross pathology, e.g., polyp, myoma, growth, etc. (Fig. 2).
Focused $\mathrm{OH}$ was then performed to describe endometrial appearance (atrophic, normal thick, papillary, suspicious of atypical hyperplasia or cancer), vasculature (normal, congestion, petechiae, ecchymosis, or abnormal suspicious vascular pattern), and color (whitish, pink, reddish, or dark red; Figs. 3 and 4). The scope was finally gradually withdrawn with confirmation of previous findings. Then a 5-mm uterine curette or a 4-mm Novak curette with suction was introduced in multiprous uterus or nulliprous uterus, respectively, for endometrial biopsy (office sample, OS) from the anterior and/or the posterior walls of the uterus just below the fundus and directed towards any suspicious area previously defined on hysteroscopic examination (Fig. 5).

The statistical analysis was done using SPSS 16 program. Categorical date were described as percentages and
Table 1 Characteristics of the study patients

${ }^{\mathrm{a} C}$ Comparisons were made between premenopausal groups only.

$N A$ Not applicable

\begin{tabular}{lllllc}
\hline & Global & $35-40$ & 40 or more & Menopausal & Sig. \\
\hline Mean age (years) & $45.3(7.9)$ & $36.4(1.5)$ & $45.6(4.2)$ & $55.6(8.3)$ & NA \\
Parity & $6.3(3.1)$ & $4.7(2.2)$ & $6.6(3)$ & $7.6(3.3)$ & 0.000 \\
Abortions & $1.3(1.5)$ & $0.9(1.2)$ & $1.4(1.6)$ & $1.3(1.5)$ & 0.06 \\
Nulliparity & $3.1 \%$ & $4.3 \%$ & $2.9 \%$ & $1.8 \%$ & 0.72 \\
Contraceptive use & $21 \%{ }^{\mathrm{a}}$ & $30 \%$ & $17 \%$ & $\mathrm{NA}$ & $0.04^{\mathrm{a}}$ \\
Progestin treatment & $37 \%$ & $37 \%$ & $39 \%$ & $31 \%$ & 0.5 \\
Previous D\&C & $31 \%$ & $27 \%$ & $36 \%$ & $20 \%$ & 0.051 \\
Hypertension & $18.6 \%$ & $4.3 \%$ & $19.4 \%$ & $35 \%$ & 0.000 \\
DM & $10 \%$ & $4.3 \%$ & $8.2 \%$ & $22 \%$ & 0.003 \\
BMI & $30.6(6.3)$ & $28.4(6)$ & $30.7(5.7)$ & $33(7.4)$ & 0.000 \\
Obesity(BMI>/=30) & $51 \%$ & $37 \%$ & $53 \%$ & $62 \%$ & 0.000 \\
\hline
\end{tabular}


Table 2 Transvaginal sonographic findings.
${ }^{a}$ Either thick endometrium or focal lesion

${ }^{\mathrm{b}}$ At $5 \mathrm{~mm}$ cut off level

\begin{tabular}{llllll}
\hline & Global & $35-40$ & 40 or more & Menopausal & Sig. \\
\hline Endometrial thickness (mm) & $10.9 \pm 5.7$ & $9.7 \pm 5.2$ & $10.3(4.8)$ & $14.2(7.6)$ & 0.000 \\
8 mm or more & $67 \%$ & $59 \%$ & $64 \%$ & $87.3 \%$ b & 0.001 \\
10 mm or more & $51 \%$ & $34 \%$ & $46 \%$ & $87.3 \%$ b & 0.000 \\
Myometrial thickness (cm) & $1.9(0.5)$ & $1.8(0.4)$ & $2(0.5)$ & $1.7(0.4)$ & 0.000 \\
Signs of adenomyosis & $41 \%$ & $27 \%$ & $52 \%$ & $24 \%$ & 0.000 \\
Focal lesion & $21 \%$ & $16 \%$ & $21 \%$ & $29 \%$ & 0.187 \\
Abnormal endometrium $8 \mathrm{~mm}^{\mathrm{a}}$ & $74 \%$ & $67 \%$ & $73 \%$ & $87.3 \% \mathrm{~b}$ & 0.032 \\
Abnormal endometrium $10 \mathrm{~mm}^{\mathrm{b}}$ & $60 \%$ & $43 \%$ & $59 \%$ & $87.3 \% \mathrm{~b}$ & 0.000 \\
Fibroid & $17 \%$ & $10 \%$ & $21 \%$ & $13 \%$ & 0.072 \\
Ovarian mass & $6.4 \%$ & $8.6 \%$ & $5.9 \%$ & $5.5 \%$ & 0.81 \\
\hline
\end{tabular}

compared with chi square and exact Fischer tests. Continuous data were described as mean $\pm \mathrm{SD}$ or median (according to data distribution) and compared using $t$ test, Man-Whitney test, and analysis of variance test with least significant difference post hock test when appropriate. Correlation was used when appropriate. The diagnostic performance is calculated using $2 \times 2$ tables using EB as the gold standard for diagnosing hyperplasia or cancer and the combined hysteroscopy and biopsy for diagnosing focal lesion.

\section{Results}

The characteristics of the study patients are shown in Table 1. Only five cases $(1.7 \%)$ had failed $\mathrm{OH}$ with success rate of (295/300) 98.3\% while 15 cases had failed OS with success rate of (295/310) 95\%. The results of TVS, OH, and EB examinations are summarized in Tables 2, 3, and 4. Abnormal findings tended to increase with age with more prevalence of precancerous and cancerous lesions in the postmenopausal group.
Table 3 Office hysteroscopic findings

\begin{tabular}{lccccc}
\hline & Global & $35-40$ & 40 or more & Menopausal & Sig. \\
\hline Appearance & & & & & \\
Atrophic & $2 \%$ & $1.4 \%$ & $1.8 \%$ & $3.6 \%$ & 0.64 \\
Normal & $58.3 \%$ & $66 \%$ & $59 \%$ & $43.6 \%$ & 0.02 \\
Thick & $32.5 \%$ & $30 \%$ & $33 \%$ & $36.4 \%$ & 0.62 \\
Plypoid & $4.4 \%$ & $2.9 \%$ & $5.3 \%$ & $3.6 \%$ & 0.67 \\
Suspecious & $2.7 \%$ & $0 \%$ & $0.6 \%$ & $13 \%$ & 0.000 \\
Vasculature & & & & & \\
Normal & $24 \%$ & $21 \%$ & $25 \%$ & $22 \%$ & 0.76 \\
Congestion & $41 \%$ & $47 \%$ & $37 \%$ & $47 \%$ & 0.22 \\
Petechiae and Ecchymosis & $29 \%$ & $30 \%$ & $33.5 \%$ & $16 \%$ & 0.052 \\
Abnormalvessles & $5.4 \%$ & $1.4 \%$ & $4.1 \%$ & $15 \%$ & 0.003 \\
Polyp & $15 \%$ & $5.7 \%$ & $14 \%$ & $29 \%$ & 0.001 \\
Submucous myomas & $13 \%$ & $5.7 \%$ & $16 \%$ & $12.7 \%$ & 0.1 \\
Either & $25 \%$ & $11.4 \%$ & $26 \%$ & $40 \%$ & 0.001 \\
Abnormal hysteroscopy & $55 \%$ & $39 \%$ & $56 \%$ & $71 \%$ & 0.001 \\
Blood clots & $17.3 \%$ & $24.3 \%$ & $14 \%$ & $18 \%$ & 0.163 \\
Adhesions & $3.7 \%$ & $2.9 \%$ & $4.7 \%$ & $1.8 \%$ & 0.56 \\
Access to tubal ostia & & & & & $0.57 \%$ \\
Both & $77.3 \%$ & $87 \%$ & $76.5 \%$ & 12.75 & 0.097 \\
One & $10.5 \%$ & $7.1 \%$ & $11.1 \%$ & $320(116)$ & 0.828 \\
Neither & $12 \%$ & $5.7 \%$ & $12.4 \%$ & $309(107)$ & \\
Fluid volume (cc) & $311(115)$ & $309(133)$ & & & \\
\hline & & & & & \\
\end{tabular}


Table 4 Results of endometrial biopsy

\begin{tabular}{|c|c|c|c|c|c|}
\hline & $\begin{array}{l}\text { Global } \\
(\%)\end{array}$ & $\begin{array}{l}35-40 \\
(\%)\end{array}$ & $\begin{array}{l}40 \text { or more } \\
(\%)\end{array}$ & $\begin{array}{l}\text { Menopausal } \\
(\%)\end{array}$ & Sig. \\
\hline Insufficient & 2.4 & 2.9 & 2.9 & 0 & 0.439 \\
\hline Proliferative & 35.4 & 41.4 & 38.8 & 18.2 & 0.005 \\
\hline Secretory & 13 & 21.4 & 12.4 & 5.5 & 0.029 \\
\hline Simple hyperplasia & 34.2 & 24.3 & 35.3 & 43.6 & 0.045 \\
\hline Atypical hyperplasia & 3.4 & 1.4 & 1.8 & 10.9 & 0.003 \\
\hline $\begin{array}{l}\text { Cancer } \\
\text { Others }\end{array}$ & 1.4 & 0 & 0 & 7.3 & 0.000 \\
\hline Atrophy & 4 & 2.9 & 3.5 & 5.4 & 0.732 \\
\hline Endometritis & 2 & 1.4 & 1.8 & 3.6 & 0.169 \\
\hline TB endometritis & 0.7 & 1.4 & 0.6 & 0 & 0.342 \\
\hline Polyp & 2.4 & 1.4 & 1.2 & 5.5 & 0.03 \\
\hline Submucous myoma & 2.4 & 1.4 & 2.9 & 3.6 & 0.274 \\
\hline $\begin{array}{c}\text { Remnants of } \\
\text { conception }\end{array}$ & 1.4 & 2.9 & 1.2 & 0 & 0.372 \\
\hline Menstruating & 0.3 & 0 & 0.6 & 0 & 0.23 \\
\hline
\end{tabular}

The diagnostic performance of the different methods in for either focal lesion or hyperplasia and cancer is shown in Table 5. OH showed better accuracy and agreement with histologic diagnosis of hyperplasia or cancer with larger area under the curve (AUC). It was much better than VUS and EB in diagnosing focal lesions with much better accuracy and agreement and larger AUC. The patient response to every procedure together with physician satisfaction is summarized in Table 6.

\section{Discussion}

Thanks for the development in optics that allowed the use of small caliber instruments that could pass through the cervix
Table 6 Patient and physician satisfaction with the different procedures

\begin{tabular}{lllll}
\hline & TVS & OH & EB & Sig. \\
\hline Duration (min) & $3.47(0.78)$ & $3.6(0.97)$ & $2.14(0.33)$ & 0.000 \\
Pain score & $1.4(0.5)$ & $3.25(0.8)$ & $4.67(1)$ & 0.000 \\
Patient acceptance & & & & \\
Easy & $85.1 \%$ & $23.1 \%$ & $2.7 \%$ & 0.000 \\
Fair & $14.6 \%$ & $61.7 \%$ & $39.7 \%$ & 0.000 \\
With difficulty & $0.3 \%$ & $15.3 \%$ & $48.5 \%$ & 0.000 \\
Not accepted & $0 \%$ & $0 \%$ & $4.1 \%$ & 0.000 \\
Not at all & $0 \%$ & $0 \%$ & $0.3 \%$ & 0.000 \\
The procedure & & & & \\
Easy & $95 \%$ & $44.1 \%$ & $14 \%$ & 0.000 \\
Uncomfortable & $5 \%$ & $37.3 \%$ & $23.4 \%$ & 0.000 \\
Painful & $0 \%$ & $18.6 \%$ & $62.7 \%$ & 0.000 \\
Vagal reaction & $0 \%$ & $1.7 \%$ & $5.4 \%$ & 0.01 \\
Physician satisfaction & $9.7(0.5)$ & $9.6(0.9)$ & $\mathrm{NA}$ & 0.8 \\
\hline
\end{tabular}

without the need of dilatation. This allowed the use of hysteroscopy in the office in a one-stop setting where all the investigations needed could be done at the time of presentation with the possibility of see-and-treat policy [6]. The addition of office hysteroscopy to vaginal sonography in the initial evaluation of abnormal uterine bleeding was associated with decrease number of visits with shorter duration to diagnosis [7]. In a qualitative trial, most women preferred office hysteroscopy for varying reasons as they could cope without anesthesia, dislike of general anesthesia, do not like to wait, or do not like to be admitted to hospital [8].

This study was performed by the conventional $\mathrm{OH}$; but nowadays, we perform all $\mathrm{OH}$ with the vaginoscopic approach which seems less painful and well tolerated by the patients. Nevertheless, in this study, we did not use any pre

Table 5 Diagnostic performance of different methods in diagnosing hyperplasia and focal lesions

\begin{tabular}{lccccccccc}
\hline & SN\% & SP\% & PPV\% & NPV\% & DA\% & PLR & NLR & Kap. & AUC \\
\hline Focal lesion & & & & & & & & \\
Focal lesion at US & 42 & 87 & 55 & 80 & 75 & 3.2 & 0.67 & 0.31 & 0.65 \\
Abnormal US 8 mm & 85 & 30 & 32 & 84 & 45 & 1.2 & 0.5 & 0.1 & 0.574 \\
Abnormal US 10 mm & 81 & 47 & 37 & 87 & 57 & 1.5 & 0.4 & 0.21 & 0.643 \\
OH myoma or polyp & 91 & 100 & 100 & 97 & 98 & 91 & 0.09 & 0.94 & 0.96 \\
EB & 17 & 100 & 100 & 69 & 78 & 17 & 0.83 & 0.24 & 0.59 \\
Hyperplasia and cancer & & & & & & & \\
Thick end. 8 mm & 82 & 42 & 48 & 78 & 58 & 1.4 & 0.43 & 0.22 & 0.612 \\
Thick end 10 mm & 74 & 63 & 56 & 79 & 67 & 2 & 0.41 & 0.36 & 0.674 \\
OH thick or suspicious endometrium & 76 & 83 & 75 & 84 & 80 & 4.5 & 0.29 & 0.6 & 0.77 \\
Abnormal OH & 85 & 65 & 61 & 87 & 73 & 2.4 & 0.23 & 0.47 & 0.73 \\
\hline
\end{tabular}


or intraprocedure analgesia or anesthesia as most studies suggests that $\mathrm{OH}$ in experienced hands is a well-tolerated technique and requires the use of analgesics only in selected patients [9]. Office hysteroscopy was well tolerated by our patients with mean pain score of $3.25 \pm 0.8$ which is comparable to previous studies with a range of $3-4.8$ with variable caliber of the hysteroscopes used [10-14]. The procedure also has high patient acceptance with $85 \%$ of patients had easy or faire acceptance and in the other $15 \%$ it was accepted with some difficulty. The corresponding figures were $88.7 \%$ and $83 \%$ with others $[11,13]$. The addition of office hysteroscopy to the initial evaluation was associated with decrease number of visits. Our results are intermediate in comparison to previous trials regarding hysteroscopic diagnosis of endometrial hyperplasia with $80 \%$ diagnostic accuracy. Some trials had low-diagnostic accuracy of 59\% [15], others had comparable accuracy of $73 \%$ [16], 79\% [17], and $81 \%$ [18] while others had higher accuracy of $90 \%$ [19] or $96 \%$ [20]. This could be explained partially by difference in patient population as Loizzi et al. [21] had a sensitivity of $100 \%$ in a population of postmenopausal women with bleeding and thick endometrium. It was found that combining endometrial biopsy and finding of focal lesion in vaginal sonography missed about $50 \%$ of focal lesions in our trial. Vaginal sonography had $42 \%$ sensitivity in detecting focal lesions. Previous studies had very wide range of sensitivity ranging from $12 \%$ to $86 \%[22,23]$, with many of them having very near figures to our study ranging from $39 \%$ to $50 \%[24,25]$. This was also the case for endometrial biopsy which detected only $17 \%$ of focal lesions and this also was comparable to previous trials with detection rate varying from $11 \%$ to $19 \%[19,26]$.

Considering low-resource countries like Egypt with high parity and consequently very high load of obstetric cases (the average rate of deliveries in our hospital is 18,000 per year), it is crucial to decrease the inpatient case load with adopting policies like one-stop outpatient service. This also much decrease the costs associated with the inpatient service.

In conclusion, the addition of office hysteroscopy in initial evaluation of women with abnormal uterine bleeding appears very beneficial as it allows complete diagnosis in fewer visits within shorter duration with the possibility of see-and-treat action and subsequently saving of the inpatient hospital resources especially in low-resource high-load countries. Regarding endometrial pathology, if performed alone, $\mathrm{OH}$ is superior to TVS in all diagnostic indices except being less sensitive. If combined with TVS, OH improves all diagnostic indices. As regards intrauterine lesions, $\mathrm{OH}$ is superior to TVS, OS, and even histopathology in detection of IU lesions. Future research should focus on comparing the diagnostic accuracy of $\mathrm{OH}$ to 4-D ultrasonography or MRI.

\section{References}

1. Collins S, Arulkumeran S, Hayes K, et al. eds. (2008) Normal menstruation and its disorders. In: Oxford handbook of obstetrics and gynecology. Oxford, OUP, 483-500

2. ACOG (2002) Guidelines for wome's health care, 2nd edn. ACOG, Washington

3. Kremer C, Duffy S, Moroney M (2000) Patient satisfaction with outpatient hysteroscopy versus day case hysteroscopy: randomized controlled trial. BMJ 320:279-282

4. Darwish AM, Makhlouf AM, Youssof AA, Gadalla HA (1999) Hysteroscopic myometrial biopsy in unexplained abnormal uterine bleeding. Eur J Obstet Gynecol Reprod Biol 86(2):139-143

5. Darwish AM, Youssef AA (1999) Screening sonohysterography in infertility. Gynecol Obstet Invest 48(1):43-47

6. Siristatidis C, Chrelias C (2011) Feasibility of office hysteroscopy through the "see and treat technique" in private practice: a prospective observational study. Arch Gynecol Obstet 283 (4):819-823

7. Böttcher B, Brown VA (2002) Postmenopausal bleeding: management by transvaginal ultrasound scan or outpatient hysteroscopy? Gynaecol Endosc 11:245-249

8. Morgan M, Dodds W, Wolfe Ch, Raju S (2004) Women's views and experiences of outpatient hysteroscopy: implications for a patient-centered service. Nurs Heal Sci 6:315-320

9. Cicinelli E (2010) Hysteroscopy without anesthesia: review of recent literature. J Minim Invasive Gynecol 17(6):703708

10. Diniz DB, Depes Dde B, Pereira AM, David SD, Lippi UG, Baracat FF, Lopes RG (2010) Pain evaluation in office hysteroscopy: comparison of two techniques. Rev Bras Ginecol Obstet 32 (1):26-32

11. Mcllwaine K, Readman E, Cameron M, Maher P (2009) Outpatient hysteroscopy: factors influencing post-procedure acceptability in patients attending a tertiary referral centre. Aust N Z J Obstet Gynaecol 49(6):650-652

12. van Dongen $\mathrm{H}$, de Kroon $\mathrm{CD}$, van den Tillaart SA, Louwé LA, Trimbos-Kemper GC, Jansen FW (2008) A randomised comparison of vaginoscopic office hysteroscopy and saline infusion sonography: a patient compliance study. BJOG 115 (10):1232-1237

13. Van den Bosch T, Verguts J, Daemen A, Gevaert O, Domali E, Claerhout F, Vandenbroucke V, De Moor B, Deprest J, Timmerman D (2008) Pain experienced during transvaginal ultrasound, saline contrast sonohysterography, hysteroscopy and office sampling: a comparative study. Ultrasound Obstet Gynecol 31(3):346-351

14. Cordeiro A, Condeço R, Leitão C, Sousa F, Coutinho S, Docarmosilva M, Bernardo MJ, Mira R (2009) Office hysteroscopy after ultrasonographic diagnosis of thickened endometrium in postmenopausal patients. Gynecol Surg 6:317-322

15. Ekin M, Karayalçın R, Özcan S, Özcan U (2007) Transvaginal ultrasonography and office hysteroscopic findings and their hystopathologic correlation in asymptomatic and symptomatic postmenopausal women. Med J Bakirköy 3:2

16. Lasmar RB, Barrozo PR, de Oliveira MA, Coutinho ES, Dias R (2006) Validation of hysteroscopic view in cases of endometrial hyperplasia and cancer in patients with abnormal uterine bleeding. J Minim Invasive Gynecol 13(5):409-412

17. Wang CJ, Mu WC, Yuen LT, Yen CF, Soong YK, Lee CL (2007) Flexible outpatient hysterofibroscopy without anesthesia: a feasible and valid procedure. Chang Gung Med J 30 (3):256-262 
18. Paschopoulos M, Lolis ED, Alamanos Y, Koliopoulos G, Paraskevaidis E (2001) Vaginoscopic hysteroscopy and transvaginal sonography in the evaluation of patients with abnormal uterine bleeding. J Am Assoc Gynecol Laparosc 8(4):506-510

19. Angioni S, Loddo A, Milano F, Piras B, Minerba L, Melis GB (2008) Detection of benign intracavitary lesions in postmenopausal women with abnormal uterine bleeding: a prospective comparative study on outpatient hysteroscopy and blind biopsy. J Minim Invasive Gynecol 15(1):87-91

20. Ceci O, Bettocchi S, Pellegrino A, Impedovo L, Di Venere R, Pansini N (2002) Comparison of hysteroscopic and hysterectomy findings for assessing the diagnostic accuracy of office hysteroscopy. Fertil Steril 78(3):628-631

21. Loizzi V, Bettocchi S, Vimercati A, Ceci O, Rossi C, Marello F, Greco P (2000) Hysteroscopic evaluation of menopausal women with endometrial thickness of $4 \mathrm{~mm}$ or more. J Am Assoc Gynecol Laparosc 7(2):191-195

22. Timmermans A, Gerritse MB, Opmeer BC, Jansen FW, Mol BW, Veersema S (2008) Diagnostic accuracy of endometrial thickness to exclude polyps in women with postmenopausal bleeding. J Clin Ultrasound 36(5):286-290

23. Georgantopoulou C, Simm A, Roberts M (2008) Transvaginal saline hysterosonography: a comparison with local anaesthetic hysteroscopy for the diagnosis of benign lesions associated with menorrhagia. Gynecol Surg 5:27-34

24. Pasqualotto EB, Margossian H, Price LL, Bradley LD (2000) Accuracy of preoperative diagnostic tools and outcome of hysteroscopic management of menstrual dysfunction. J Am Assoc Gynecol Laparosc 7(2):201-209

25. Mukhopadhayay S, Bhattacharyya SK, Ganguly RP, Patra KK, Bhattacharya N, Barman SC (2007) Comparative evaluation of perimenopausal abnormal uterine bleeding by transvaginal sonography, hysteroscopy and endometrial biopsy. J Indian Med Assoc 105(11):624, 626, 628

26. Verrotti C, Benassi G, Caforio E, Nardelli GB (2008) Targeted and tailored diagnostic strategies in women with perimenopausal bleeding: advantages of the sonohysterographic approach. Acta Biomed 79(2):133-136 